\title{
Disease knowledge level is a noteworthy risk factor of anxiety and depression in patients with chronic obstructive pulmonary disease: a cross-sectional study
}

\author{
Qiao Zhang ${ }^{1}$, Jiangrong Liao ${ }^{2}$, Xiuqing Liao ${ }^{3}$, Xiuling Wư ${ }^{4}$ Min Wan ${ }^{1}$, Changzheng Wang ${ }^{1}$ and Qianli Ma ${ }^{1 *}$
}

\begin{abstract}
Background: Risk factors of anxiety and depression symptoms in patients with chronic obstructive pulmonary disease (COPD) have been widely researched, but most of them cannot be addressed clinically. The aim of this study was to investigate whether COPD knowledge level is a risk factor of anxiety and/or depression in COPD patients in addition to functional capacity and quality of life, and to determine the key topics of COPD knowledge.

Methods: A total of 364 COPD patients from four centers were recruited into this cross-sectional survey. Subjects' general medical information, assessments of lung function, dyspnea, quality of life, and exercise capacity, and responses to the Hospital Anxiety and Depression Scale (HAD) and the Bristol COPD Knowledge Questionnaire (BCKQ) were collected. Partial correlation analysis was performed, and a multivariable model testing risk factors of anxiety and depression as well as a multivariable model of 13 topics of knowledge derived from BCKQ were constructed.

Results: Subjects with anxiety or depression were more likely to have less COPD knowledge. Partial correlation analysis revealed that HAD score was negatively correlated with BCKQ score (rho $=-0.153, P=0.004)$. BCKQ score was significant in the multivariable model that tested risk factors of anxiety and depression $(P=0.001, \mathrm{OR}=0.944)$. Topics of epidemiology $(P<0.001, \mathrm{OR}=0.653)$ and infections $(P=0.006, \mathrm{OR}=0.721)$ were significant in the multivariable model evaluating 13 topics.
\end{abstract}

Conclusions: The level of patients' disease knowledge is a significant risk factor of anxiety and depression in COPD patients. Epidemiology and infections are key topics of COPD knowledge to target in the Chinese population.

Trial registration: ChiCTR-OCS-12002518

Keywords: COPD, Knowledge, Anxiety, Depression, Comorbidities

\section{Background}

Anxiety and depression are common psychological disturbances affecting a substantial number of patients with COPD, with reported prevalence rates of $10-57 \%$ for anxiety and $10-59 \%$ for depression [1-4]. Both are significantly associated with increased physical disability and morbidity, decreased health status, and decreased compliance with medical treatment [4-8].

\footnotetext{
* Correspondence: cqmql@163.com

${ }^{1}$ Institute of Respiratory Diseases, Xinqiao Hospital, Third Military Medical University, Chongqing 400037, China

Full list of author information is available at the end of the article
}

Successful psychological or psychiatric interventions could address anxiety and depression. Exploring the risk factors of COPD patients with anxiety and/or depression may be valuable for understanding disease processes and improving disease prevention.

Some risk factors of anxiety and depression symptoms in COPD patients have been widely researched, including younger age, female gender, current smoker status, bronchitic phenotype, more advanced disease, cardiovascular comorbidities, and worse functional capacity and quality of life $[1,2,9,10]$. However, the overall explanatory value of these risk factors is weak. New risk factors that

\section{Ciomed Central}

(c) 2014 Zhang et al.; licensee BioMed Central Ltd. This is an Open Access article distributed under the terms of the Creative Commons Attribution License (http://creativecommons.org/licenses/by/2.0), which permits unrestricted use, distribution, and reproduction in any medium, provided the original work is properly credited. The Creative Commons Public Domain Dedication waiver (http://creativecommons.org/publicdomain/zero/1.0/) applies to the data made available in this article, unless otherwise stated. 
might have previously been ignored should be investigated. The finding that COPD patients' anxiety and depression symptoms improved following pulmonary rehabilitation provides a valuable clue [11-13].

Patient education, an essential element of pulmonary rehabilitation, relates to improving COPD patients' disease knowledge level [14]. The relief of anxiety and depression symptoms may be associated with patient education affecting COPD patients' disease knowledge level. We have found that COPD patients with greater disease knowledge had fewer symptoms of anxiety and depression in our COPD disease management plan (data not shown). We hypothesize that COPD patients' disease knowledge (including knowledge of epidemiology, aetiology, symptoms, treatment, and disease management of COPD) is another risk factor related to anxiety and depression symptoms.

In this cross-sectional study, we investigate whether COPD knowledge level is a risk factor of anxiety and depression symptoms in COPD patients alongside functional capacity and quality of life. We examined the effect of 13 key topics of COPD knowledge measured by $\mathrm{BCKQ}$, including (1) epidemiology, (2) aetiology, (3) symptom, (4) breathlessness, (5) phlegm, (6) infections, (7) exercise, (8) smoking, (9) vaccination, (10) inhaled bronchodilators, (11) antibiotics, (12) oral steroids, and (13) inhaled steroids [15].

\section{Methods}

\section{Study design}

This study was a cross-sectional survey. It was conducted at four centers in two districts, in accordance with the Declaration of Helsinki and good clinical practice guidelines, and was approved by the medical ethics committee of the second affiliated hospital of Third Military Medical University. All patients were enrolled from an outpatient clinic and gave informed consent. The study was registered in the Chinese Clinical Trial Registry (www.chictr.org, Registration no: ChiCTR-OCS-12002518).

\section{Participants and measurements}

All patients with COPD were consecutively recruited from four outpatient clinics in Guizhou Province, Chongqing Municipality, China from September 2012 to June 2013. All participants were diagnosed with COPD in accordance with the Global Initiative for Chronic Obstructive Lung Disease strategy document [16] and confirmed by postbronchodilator FEV1/FVC of less than 0.7. Patients with self-reported comorbidities or COPD exacerbation in the previous 4 weeks were excluded.

Subjects' general medical information was collected, including age, gender, duration of disease, smoking history, and highest educational qualification. Lung function tests were performed according to American Thoracic Society/
European Respiratory Society (ATS/ERS) guidelines [17]. In addition, patient-reported outcomes were measured, including assessment of dyspnea (modified Medical Research Council Dyspnea scale (mMRC)) [18], psychological disturbance (HAD scale) [19], quality of life (COPD Assessment Test (CAT)) [20], and BCKQ [15]. All questionnaires were completed by subjects independently with adequate space, a firm writing surface, and a pencil. If the patient was illiterate or had other complications that prevented them from completing the questionnaire, the investigator obtained patient responses by reading each question out loud verbatim, followed by the corresponding response categories, and entering the patient's responses. The investigator did not influence patient responses. Exercise capacity was assessed using the sixminute walking distance test (6MWD) carried out according to ATS guidelines [21]. Subjects were ordered to walk as rapidly as possible along a solid and flat corridor for 6 minutes.

\section{Measurement of anxiety and depression}

The HAD scale was used to assess anxiety and depression symptoms in all eligible subjects [19]. It has been used extensively to screen psychiatric morbidity and has high validity when used as a screening instrument in outpatients [22]. HAD consists of two 7-item subscales: 7 questions relate to anxiety (HAD-A) and 7 to depression (HAD-D). Scores range from 0 to 21 for each subscale, and a score of 8 or higher on either subscale indicates possible pathology. Using this cutoff, HAD shows high sensitivity and specificity in Chinese patients [23].

Measurement of COPD patients' disease knowledge level BCKQ was used to assess eligible COPD patients' disease knowledge level. It consists of 13 subscales, each of which assesses a topic of COPD knowledge: (1) epidemiology, (2) aetiology, (3) symptom, (4) breathlessness, (5) phlegm, (6) infections, (7) exercise, (8) smoking, (9) vaccination, (10) inhaled bronchodilators, (11) antibiotics, (12) oral steroids, and (13) inhaled steroids. Each topic contains five questions. Scores range from 0 to 65 , with higher scores suggesting higher disease knowledge level in COPD patients. BCKQ tests knowledge appropriate for COPD patients and can be used as a broad crosssectional survey instrument [15]. Prior to this study, we translated, retranslated, and piloted the questionnaire in a Chinese population [24].

\section{Statistical analysis}

Means and standard deviations were computed for variables including age, pack-year history, duration of COPD, CAT, mMRC, BCKQ, FEV1, FEV1\%, postFEV1, postFEV1\%, and 6MWT. An independent samples t-test was used to compare continuous variables between groups 
(with or without anxiety/depression). A chi-square test was used to test categorical variables. Spearman's correlation coefficients were calculated between HAD total score and descriptor variables. Partial correlation analysis was performed to assess the correlation between HAD and target descriptor variables while controlling for the effect of other variables. [Additional file 1 provides the details of this partial correlation analysis]. A combined analysis of patient-reported outcomes, clinically based descriptors, and lung function test results was performed using a stepwise logistic regression model. The $P$-values necessary for entry into the model and to remain in the model were both $P<0.1$. The same method was used to assess the 13 topics of the BCKQ.

\section{Results}

\section{Subject demographics}

A total of 416 subjects were eligible for the study. Fifty two subjects refused to be included. A total of 364 subjects provided informed consent and entered the study. Five of these subjects were excluded due to inadequate completion or loss of data. Therefore, 359 participants were analyzed. Thirty two participants were female. The mean age was $65.64 \pm 7.60$ years. A total of 95 patients (26.46\%) had an HAD-A and/or HAD-D score of $\geq 8$.
The mean CAT score was $16.42 \pm 7.20$, the mean mMRC score was $1.53 \pm 0.85$, and the mean BCKQ score was $30.36 \pm 5.59$ - only $46 \%$ of the full mark possible. In total, $15.32 \%$ had educational qualifications at junior college level or above. No subjects were receiving treatment for their anxiety/depression at the time of assessment. More demographic details are listed in Table 1 . Subjects with anxiety/depression were more likely to be younger, female, to have worse quality of life, increased dyspnea, and a lower level of disease knowledge about COPD (see below).

\section{Correlation of HAD total score with characteristics of subjects}

Spearman correlation analysis revealed significant correlations between HAD score and age, gender, CAT score, mMRC score, BCKQ score, FEV1, FEV1\% predicted, postbronchodilator FEV1, post-bronchodilator FEV1\% predicted, and 6MWD.

A partial correlation analysis revealed that higher HAD total score correlated with female gender ( $\mathrm{rho}=0.376$, $P<0.001$ ), worse quality of life (CAT score, rho $=0.351$, $P<0.001$ ), increased dyspnea (mMRC, rho $=0.109, P=$ 0.042), and lower level of COPD knowledge (BCKQ, rho $=-0.153, P=0.004)$. No other variables significantly

Table 1 Characteristics of subjects stratified by presence of anxiety and/or depression status

\begin{tabular}{|c|c|c|c|c|}
\hline & \multirow[t]{2}{*}{ Total } & \multicolumn{2}{|c|}{ Anxiety and/or Depression status } & \multirow{2}{*}{$\begin{array}{c}P \\
\text { value }\end{array}$} \\
\hline & & Yes $(n=95)$ & No $(n=264)$ & \\
\hline Age, mean $\pm S D$ & $65.64 \pm 7.60$ & $64.25 \pm 7.84$ & $66.14 \pm 7.47$ & 0.038 \\
\hline Gender, n (male/female) & $327 / 32$ & $77 / 18$ & $250 / 14$ & $<0.001$ \\
\hline Pack-year history, mean \pm SD & $33.65 \pm 18.37$ & $32.46 \pm 20.28$ & $34.08 \pm 17.66$ & 0.463 \\
\hline Duration of COPD, years, mean \pm SD & $6.69 \pm 5.32$ & $6.77 \pm 6.19$ & $6.66 \pm 4.98$ & 0.859 \\
\hline CAT, mean $\pm S D$ & $16.42 \pm 7.20$ & $20.17 \pm 6.50$ & $15.06 \pm 6.97$ & $<0.001$ \\
\hline $\mathrm{mMRC}$, mean $\pm \mathrm{SD}$ & $1.53 \pm 0.85$ & $1.86 \pm 0.86$ & $1.42 \pm 0.82$ & $<0.001$ \\
\hline $\mathrm{BCKQ}$, mean $\pm \mathrm{SD}$ & $30.36 \pm 9.59$ & $26.85 \pm 9.16$ & $31.63 \pm 9.45$ & $<0.001$ \\
\hline$H A D-A$, mean $\pm S D$ & $3.54 \pm 3.74$ & $7.87 \pm 3.69$ & $1.98 \pm 2.24$ & $<0.001$ \\
\hline$H A D-D$, mean $\pm S D$ & $4.17 \pm 3.76$ & $8.97 \pm 2.69$ & $2.45 \pm 2.31$ & $<0.001$ \\
\hline FEV1, L, mean \pm SD & $1.11 \pm 0.44$ & $1.04 \pm 0.41$ & $1.14 \pm 0.45$ & 0.062 \\
\hline FEV1\% predict, mean \pm SD & $42.88 \pm 25.56$ & $39.12 \pm 14.77$ & $44.23 \pm 28.36$ & 0.094 \\
\hline Post FEV1, L, mean \pm SD & $1.22 \pm 0.47$ & $1.16 \pm 0.47$ & $1.24 \pm 0.46$ & 0.133 \\
\hline Post FEV1\% predict, mean \pm SD & $46.77 \pm 25.88$ & $43.37 \pm 116.19$ & $48.00 \pm 28.50$ & 0.135 \\
\hline $6 \mathrm{MWD}, \mathrm{m}$, mean $\pm \mathrm{SD}$ & $429.64 \pm 115.39$ & $431.38 \pm 124.34$ & $429.01 \pm 112.24$ & 0.864 \\
\hline Primary school, n (\%) & $106(29.53 \%)$ & $27(28.42 \%)$ & 79 (29.92\%) & 0.783 \\
\hline Junior high school, n (\%) & 129 (35.93\%) & $42(44.21 \%)$ & 87 (32.95\%) & 0.050 \\
\hline Senior high school, n (\%) & $59(16.43 \%)$ & $14(14.74 \%)$ & 45 (31.78\%) & 0.603 \\
\hline Junior college or above, n (\%) & $55(15.32 \%)$ & $8(8.42 \%)$ & $47(17.80 \%)$ & 0.029 \\
\hline Other, n (\%) & $10(2.79 \%)$ & $4(4.21 \%)$ & $6(2.27 \%)$ & 0.301 \\
\hline
\end{tabular}

Abbreviations: CAT COPD Assessment Test, $m M R C$ modified Medical Research Council, BCKQ Bristol COPD Knowledge Questionnaire, HAD Hospital Anxiety and Depressive Scale, HAD-A HAD-anxiety, HAD-D HAD-Depression, FEV1 Forced Expiratory Volume in 1 Second, postFEV1 post-bronchodilator FEV1, 6MWD Six-Minute Walking Distance Test; Definition of Anxiety and/or Depression Status: HAS-A $\geq 8$ and/or HAD-D score $\geq 8$. 
correlated with HAD scores, including age, smoke history, duration of COPD, FEV1, FEV1\% predicted, postbronchodilator FEV1, post-bronchodilator FEV1\% predicted, and 6MWD (Table 2).

\section{Risk factors of anxiety and depression}

A multivariable model testing risk factors of anxiety and depression explored factors including age, gender, CAT, mMRC, BCKQ score, FEV1, FEV1\% predicted, post-bronchodilator FEV1, post-bronchodilator FEV1\% predicted, and 6MWD. Gender ("male" $=0$, "female" $=1$, $P=0.001, \mathrm{OR}=3.781)$, CAT score $(P<0.001, \mathrm{OR}=1.087)$, mMRC score $(P=0.050, \mathrm{OR}=1.386)$ and BCKQ score $(P=0.001, \mathrm{OR}=0.944)$ were significant in this model. In accordance with our hypotheses, level of COPD knowledge was a risk factor of anxiety and/or depression symptoms in COPD patients alongside functional capacity and quality of life. However, the overall predictive capability of the model was very weak (Hosmer and Lemeshow Test, $P=0.128)$.

\section{Topics of COPD knowledge and subjects' anxiety or} depression

The 13 topics of COPD knowledge measured by BCKQ were assessed. Subjects with anxiety and/or depression had lower scores in topics (1) epidemiology, (3) symptom, (4) breathlessness, (5) phlegm, (6) infections, (9) vaccination, (10) inhaled bronchodilators, and (11) antibiotics. These topics were used to construct the multivariable model. (1) Epidemiology $(P<0.001, \mathrm{OR}=0.653)$ and $(6)$

Table 2 Correlation between HAD total score and subject characteristics

\begin{tabular}{lcccc}
\hline & Spearman's rho & $\begin{array}{c}\boldsymbol{P} \\
\text { value }\end{array}$ & $\begin{array}{c}\text { Partial } \\
\text { correlations }\end{array}$ & $\begin{array}{c}\boldsymbol{P} \\
\text { value }\end{array}$ \\
\hline Age & -0.122 & 0.021 & -0.036 & 0.509 \\
Gender $^{\dagger}$ & 0.295 & 0.000 & 0.376 & $<0.001$ \\
Pack-year history & -0.029 & 0.586 & 0.051 & 0.344 \\
Duration of COPD & 0.014 & 0.799 & -0.043 & 0.419 \\
CAT & 0.495 & 0.000 & 0.351 & $<0.001$ \\
mMRC & 0.309 & 0.000 & 0.109 & 0.042 \\
BCKQ & -0.217 & 0.000 & -0.153 & 0.004 \\
FEV1 (L) & -0.157 & 0.003 & -0.063 & 0.243 \\
FEV1\% predict & -0.174 & 0.001 & 0.043 & 0.425 \\
PostFEV1 (L) & -0.145 & 0.006 & 0.070 & 0.194 \\
PostFEV1\% predict & -0.158 & 0.003 & -0.051 & 0.341 \\
6MWT & -0.112 & 0.034 & 0.014 & 0.789 \\
\hline Abbreviations: CAT & & &
\end{tabular}

Abbreviations: CAT COPD Assessment Test, $m M R C$ modified Medical Research Council, BCKQ Bristol COPD Knowledge Questionnaire, HAD Hospital Anxiety and Depressive Scale, FEV1 Forced Expiratory Volume in 1 Second, postFEV1 post-bronchodilator FEV1, 6MWD Six-Minute Walking Distance Test.

${ }^{+}$Set "male" $=0$, "female" $=1$.
Infections $(P=0.006, \mathrm{OR}=0.721)$ were significant in this model. The $P$ value of Hosmer and Lemeshow Test of this model was 0.919 (Table 3).

\section{Discussion}

In this study, $26.46 \%$ of COPD patients had anxiety and/ or depression. Subjects with anxiety and/or depression were significantly more likely to be younger, female, and to have worse quality of life and increased dyspnea. This is consistent with previous studies. Worse anxiety and/ or depression symptoms (with higher HAD total scores) significantly correlated with younger age, female patients, worse quality of life, increased dyspnea, increased severity of airway limitation, and lower 6MWD $[2,9,10]$.

The key finding of this study is that the level of patients' COPD knowledge was another risk factor of anxiety and/or depression alongside functional capacity, quality of life, and gender. A higher HAD score correlated with lower COPD knowledge (BCKQ, rho $=-0.153, P=0.004)$. Previous studies mainly focused on the relationship between anxiety and/or depression and COPD patients' clinical features, including patient-reported outcomes, demographic factors, and objective measures $[2,9,10,25]$. Most risk factors identified previously could not be addressed. The ECLIPSE study concluded "subjective measures, represented by quality of life and symptom, were stronger determinants of depression than objective measures, such as lung function and biologic and physiologic markers" [10]. Level of COPD knowledge, a subjective

Table 3 Topic score in BCKQ for subjects stratified by presence of anxiety and/or depression status

\begin{tabular}{lcccc}
\hline Topic & Total & \multicolumn{2}{c}{$\begin{array}{c}\text { Anxiety and/or depression } \\
\text { status }\end{array}$} & $\begin{array}{c}\boldsymbol{P} \\
\text { value }\end{array}$ \\
\cline { 3 - 4 } & & Yes (n= 95) & No ( $\mathbf{n = 2 6 4 )}$ & \\
\hline 1 Epidemiology & & \\
& $2.91 \pm 1.06$ & $2.39 \pm 1.07$ & $3.10 \pm 1.02$ & $<0.001$ \\
2 Aetiology & $3.56 \pm 1.04$ & $3.37 \pm 1.07$ & $3.63 \pm 1.03$ & 0.098 \\
3 Symptom & $2.79 \pm 1.01$ & $2.42 \pm 0.88$ & $2.92 \pm 1.04$ & 0.001 \\
4 Breathlessness & $2.92 \pm 0.91$ & $2.72 \pm 0.96$ & $2.99 \pm 0.88$ & 0.047 \\
5 Phlegm & $3.23 \pm 1.32$ & $2.78 \pm 1.42$ & $3.39 \pm 1.26$ & 0.003 \\
6 Infections & $2.28 \pm 1.11$ & $1.83 \pm 1.10$ & $2.44 \pm 1.09$ & $<0.006$ \\
7 Exercise & $2.96 \pm 1.22$ & $2.78 \pm 1.20$ & $3.03 \pm 1.23$ & 0.173 \\
8 Smoking & $2.97 \pm 0.95$ & $2.80 \pm 0.99$ & $3.04 \pm 0.93$ & 0.102 \\
9 Vaccination & $1.75 \pm 1.15$ & $1.49 \pm 1.07$ & $1.85 \pm 1.16$ & 0.036 \\
10 Inhaled & $1.33 \pm 1.06$ & $1.03 \pm 1.05$ & $1.44 \pm 1.05$ & 0.009 \\
bronchodilators & & & & \\
11 Antibiotics & $1.48 \pm 1.11$ & $1.14 \pm 0.97$ & $1.61 \pm 1.14$ & 0.003 \\
12 Oral steroids & $1.27 \pm 1.06$ & $1.28 \pm 1.12$ & $1.27 \pm 1.04$ & 0.963 \\
13 Inhaled steroids & $0.90 \pm 0.89$ & $0.83 \pm 0.88$ & $0.92 \pm 0.90$ & 0.480
\end{tabular}

Definition of Anxiety and/or Depression Status: HAS-A $\geq 8$ and/or HAD-D score $\geq 8$.

${ }^{\dagger}$ LogisticRegression: $P<0.001, \mathrm{OR}=0.653$.

FLogisticRegression: $P=0.006, \mathrm{OR}=0.721$. 
measure, appears to be a new risk factor that was previously ignored and that can be addressed.

However, it is important to point out that the overall explanatory value of our final four-variable multivariable regression model was weak. Therefore, although we have confirmed that level of COPD knowledge was a new risk factor, none of the factors we measured strongly explained the presence of anxiety and/or depression in patients with COPD. Based on these results, we hypothesize that in COPD patients, anxiety and depression are primarily driven by the patient's perception of serious chronic disease and the mindset of facing this troubled state. Further research should be conducted to increase knowledge in this area.

There is controversy over whether the education interventions in clinical practice were efficacious. For example, in a randomized trial of exercise, stress management, and education, investigators did not find the benefit of reducing anxiety in the education group [26], while another randomized trial of cognitive behavioral therapy and COPD education reported that both forms of education were efficacious in reducing anxiety or depressive symptoms. A limited number of trials have been performed [27], all trials used different methods to educate patients, and none assessed actual change in COPD knowledge. These defects may have led to different results and points of view. The content and frequency of education as well as educational methods all require further study.

To evaluate key topics of COPD knowledge to address in educational interventions, a further logistic model based on the 13 topics of BCKQ was constructed. Although subjects with anxiety and/or depression had lower scores in (1) epidemiology, (3) symptom, (4) breathlessness, (5) phlegm, (6) infections, (9) vaccination, (10) inhaled bronchodilators, and (11) antibiotics, knowledge of topics (1) epidemiology and (6) infections was found to be a risk factor for anxiety and/or depression in COPD patients.

The epidemiology topic contains questions such as: "In COPD, the word 'chronic' means that it is severe". However, the reason that the epidemiology category was significant is unknown, we conjecture that this misunderstanding of the disease may be involved. A patient who has misunderstood the meaning of the name COPD may make incorrect interpretations, such as "I am going to die", "I am past all hope", and "All these treatments are useless to me", when he or she is experiencing dyspnea. This in turn may lead to a heightened state of physiological arousal accompanied by further sensations and misinterpretations.

The category 'infections' addresses the relationship between infections and treatment of COPD exacerbation. The causes of the significance of this factor were also unclear. We conjecture that this may be a special topic in China. Anti-inflammation and anti-infection have the same meaning for some Chinese patients. They consequently regard COPD as an infectious disease. Because most Chinese patients have easy access to antibiotics, this may result in antibiotics abuse and poor outcomes. COPD patients who understand infection in this way may have more negative thoughts and emotions than do patients who can interpret, understand, and treat COPD correctly. This suggests that patients from different cultural backgrounds may have different results.

We acknowledge the limitations in our study. First, the overall level of COPD knowledge and education was low, which accurately reflects the current situation of COPD patients in West China [24]. In addition, gender was imbalanced. The number of male patients was nearly 10 times higher than the number of female patients. This may result from the gender ratio characteristic of COPD. There was a 3:1 ratio of men to women in the epidemiological investigation, and this is comparable with that of another multicenter study held in China [28]. The influence of gender imbalance was limited to the relationship between the level of COPD knowledge and anxiety/ depression.

\section{Conclusions}

A combination of anxiety and depression symptoms is common in COPD patients. In this study, we found that the level of COPD patients' disease knowledge was a risk factor of anxiety and/or depression alongside functional capacity and quality of life. Key topics of COPD knowledge that could be addressed were (1) epidemiology and (6) infections. Relevant topics may differ in patients with different cultural backgrounds. Our study indicates that the relationship between COPD knowledge level, mental health, and education strategy is valuable to investigate in the future.

\section{Additional file}

Additional file 1: Details of the variables in partial correlations analysis. Description of data: All details of the variables in partial correlation analysis were described.

\section{Abbreviations}

COPD: Chronic obstructive pulmonary disease; BCKQ: Bristol COPD knowledge questionnaire; HAD: Hospital anxiety and depression; HAD-A: HAD-Anxiety; HAD-D: HAD-Depression; CAT: COPD assessment test; mMRC: Modified Medical Research Council Dyspnea Scale; 6MWD: Six-minute walking distance test; FEV1: Forced expiratory volume in 1 second; postFEV1: Post-bronchodilator FEV1; FVC: Forced vital capacity.

\section{Competing interests}

The authors declare that they have no conflicts of interest in relation to this article. J.R. Liao, X.L. Wu, X.Q. Liao, and M. Wan declare that they have no competing interests. Q. Zhang has received lecture fees and travel grants from AstraZeneca and GlaxoSmithKline (GSK). C.Z. Wang and Q.L. Ma have received lecture fees and travel grants from AstraZeneca, Boehringer Ingelheim, GSK, and Novartis, and they have received lecture fees from Takeda, Aerocrine, Daiichi Sankyo, and Merck Sharp \& Dohme (MSD). 


\section{Authors' contributions}

QZ drafted the manuscript, participated in patient recruitment, collection of subjects' general medical information, HAD scale, BCKQ scale, and performed the partial correlation analysis. MW constructed multivariable models testing risk factors of anxiety/depression and the 13 topics from BCKQ. QM conceived of the study, performed the statistical analysis, participated in the design and coordination of the study, and helped to draft the manuscript. $C W, J L, X L$, and $X W$ participated in the design of the study, participated in patient recruitment and collecting subjects' general medical information, HAD scale, and BCKQ scale. All authors read and approved the final manuscript.

\section{Acknowledgements}

Data collection and study operation were funded by COPD management projects of Xinqiao Hospital (2013LCXJS003). The funders had no influence on the study design, data analysis, interpretation of data, writing of the report, or the decision to submit the article for publication.

\section{Author details}

${ }^{1}$ Institute of Respiratory Diseases, Xinqiao Hospital, Third Military Medical University, Chongqing 400037, China. ${ }^{2}$ Department of Respiratory Diseases, Guizhou Aerospace Hospital, Guizhou, China. ${ }^{3}$ Department of Respiratory Diseases, Fuling Central Hospital of Chongqing, Chongqing, China. ${ }^{4}$ Department of Respiratory Diseases, Armed Police General Hospital of Chongqing, Chongqing, China.

Received: 11 January 2014 Accepted: 8 May 2014

Published: 28 May 2014

\section{References}

1. Kunik ME, Roundy K, Veazey C, Souchek J, Richardson P, Wray NP, Stanley MA: Surprisingly high prevalence of anxiety and depression in chronic breathing disorders. Chest 2005, 127:1205-1211.

2. Lou P, Zhu Y, Chen P, Zhang P, Yu J, Zhang N, Chen N, Zhang L, Wu H, Zhao J: Prevalence and correlations with depression, anxiety, and other features in outpatients with chronic obstructive pulmonary disease in China: a cross-sectional case control study. BMC Pulm Med 2012, 12:53.

3. Zeng $X$, Chen F, Liu N, Xie S: Analysis of depression and anxiety in patients with chronic obstructive pulmonart disease. Mod Prev Med 2011, 38:3242-3243. 3245 .

4. Maurer J, Rebbapragada V, Borson S, Goldstein R, Kunik ME, Yohannes AM, Hanania NA, Anxiety AWPo, Depression in C: Anxiety and depression in COPD: current understanding, unanswered questions, and research needs. Chest 2008, 134:43S-56S.

5. Dahlen I, Janson C: Anxiety and depression are related to the outcome of emergency treatment in patients with obstructive pulmonary disease. Chest 2002, 122:1633-1637.

6. Hill K, Geist R, Goldstein RS, Lacasse Y: Anxiety and depression in endstage COPD. Eur Respirat J 2008, 31:667-677.

7. Ng TP, Niti M, Tan WC, Cao Z, Ong KC, Eng P: Depressive symptoms and chronic obstructive pulmonary disease: effect on mortality, hospital readmission, symptom burden, functional status, and quality of life. Arch Intern Med 2007, 167:60-67.

8. Turan $\mathrm{O}$, Yemez B, Itil O: The effects of anxiety and depression symptoms on treatment adherence in COPD patients. Prim Health Care Res Dev 2013, 1-8. http://www.ncbi.nlm.nih.gov/pubmed/23561004.

9. Cleland JA, Lee AJ, Hall S: Associations of depression and anxiety with gender, age, health-related quality of life and symptoms in primary care COPD patients. Fam Pract 2007, 24:217-223.

10. Hanania NA, Mullerova H, Locantore NW, Vestbo J, Watkins ML, Wouters EF, Rennard SI, Sharafkhaneh A, Evaluation of CLtIPSEsi: Determinants of depression in the ECLIPSE chronic obstructive pulmonary disease cohort. Am J Respir Crit Care Med 2011, 183:604-611.

11. Cafarella PA, Effing TW, Usmani ZA, Frith PA: Treatments for anxiety and depression in patients with chronic obstructive pulmonary disease: a literature review. Respirology 2012, 17:627-638.

12. Coventry PA, Hind D: Comprehensive pulmonary rehabilitation for anxiety and depression in adults with chronic obstructive pulmonary disease: Systematic review and meta-analysis. J Psychosom Res 2007, 63:551-565.
13. Von Leupoldt A, Fritzsche A, Trueba AF, Meuret AE, Ritz T: Behavioral medicine approaches to chronic obstructive pulmonary disease. Ann Behav Med 2012, 44:52-65.

14. Spruit MA, Singh SJ, Garvey C, ZuWallack R, Nici L, Rochester C, Hill K, Holland AE, Lareau SC, Man WD, Pitta F, Sewell L, Raskin J, Bourbeau J, Crouch R, Franssen FM, Casaburi R, Vercoulen JH, Vogiatzis I, Gosselink R, Clini EM, Effing TW, Maltais F, van der Palen J, Troosters T, Janssen DJ, Collins E, Garcia-Aymerich J, Brooks D, Fahy BF: An official American Thoracic Society/European Respiratory Society statement: key concepts and advances in pulmonary rehabilitation. Am J Respir Crit Care Med 2013, 188:e13-e64.

15. White $R$, Walker $P$, Roberts $S$, Kalisky $S$, White P: Bristol COPD Knowledge Questionnaire (BCKQ): testing what we teach patients about COPD. Chron Respir Dis 2006, 3:123-131.

16. From the Global Strategy for the Diagnosis, Management and Prevention of COPD, Global Strategy for Diagnosis, Management, and Prevention of COPD. [http://www.goldcopd.org/]

17. Miller MR, Hankinson J, Brusasco V, Burgos F, Casaburi R, Coates A, Crapo R, Enright $P$, van der Grinten $C P$, Gustafsson $P$, Jensen $R$, Johnson DC, Maclntyre N, McKay R, Navajas D, Pedersen OF, Pellegrino R, Viegi G, Wanger J, Force AET: Standardisation of spirometry. Eur Respir J 2005, 26:319-338.

18. Bestall JC, Paul EA, Garrod R, Garnham R, Jones PW, Wedzicha JA: Usefulness of the Medical Research Council (MRC) dyspnoea scale as a measure of disability in patients with chronic obstructive pulmonary disease. Thorax 1999, 54:581-586.

19. Zigmond AS, Snaith RP: The hospital anxiety and depression scale. Acta Psychiatr Scand 1983, 67:361-370.

20. Jones PW, Tabberer $M$, Chen WH: Creating scenarios of the impact of COPD and their relationship to COPD Assessment Test (CAT) scores. BMC Pulm Med 2011, 11:42.

21. Laboratories ATSCOPSFCPF: ATS statement: guidelines for the six-minute walk test. Am J Respir Crit Care Med 2002, 166:111-117.

22. Bjelland I, Dahl AA, Haug TT, Neckelmann D: The validity of the Hospital Anxiety and Depression Scale. An updated literature review. J Psychosom Res 2002, 52:69-77.

23. Zheng L, Wang Y, Li H: Application of Hospital Anxiety and Depression Scale in general hospital: an analysis in reliability and validity. Shanghai Arch Psychiatry 2003, 15:264-266.

24. Wan M, Zhang Q, Li Y, Wu Y, Wang C, Ma Q: Investigation of COPD awareness in patients with newly diagnosed COPD. Acta Academiae Medicinae Militaris Tertiae 2011, 33:2527-2529.

25. Van Manen JG, Bindels PJ, Dekker FW CJIJ, van der Zee JS, Schade E: Risk of depression in patients with chronic obstructive pulmonary disease and its determinants. Thorax 2002, 57:412-416.

26. Emery CF, Schein RL, Hauck ER, Maclntyre NR: Psychological and cognitive outcomes of a randomized trial of exercise among patients with chronic obstructive pulmonary disease. Health Psychol 1998, 17:232-240.

27. Hynninen MJ, Bjerke N, Pallesen S, Bakke PS, Nordhus IH: A randomized controlled trial of cognitive behavioral therapy for anxiety and depression in COPD. Respir Med 2010, 104:986-994.

28. Zheng JP, Yang L, Wu YM, Chen P, Wen ZG, Huang WJ, Shi Y, Wang CZ, Huang SG, Sun TY, Wang GF, Xiong SD, Zhong NS: The efficacy and safety of combination salmeterol (50 microg)/fluticasone propionate (500 microg) inhalation twice daily via accuhaler in Chinese patients with COPD. Chest 2007, 132:1756-1763.

\section{doi:10.1186/1471-2466-14-92}

Cite this article as: Zhang et al.: Disease knowledge level is a noteworthy risk factor of anxiety and depression in patients with chronic obstructive pulmonary disease: a cross-sectional study. BMC Pulmonary Medicine 2014 14:92. 